\title{
Caminhos no método BPI: a incorporação da personagem Sete Ondas a partir da pesquisa de campo com baianas de escolas de samba e com o congado
}

\author{
Ways on BPI method: the character Sete Ondas' \\ incorporation from field researches among baianas \\ of samba scholls and congado
}

Maria Julia Maranzato ${ }^{1}$

Larissa Sato Turtelli ${ }^{2}$

\section{RESUMO}

O presente artigo traz a análise e reflexões das experiências vividas em um processo criativo no método BailarinoPesquisador-Intérprete, explanando o funcionamento do método através da experiência da intérprete no mesmo. São abordadas as pesquisas de campo realizadas pela intérprete com baianas de escolas de samba da cidade de Jundiaí-SP e na festa do Congado na comunidade dos Arturos, em Contagem-MG, bem como o processo de Incorporação da Personagem no método BailarinoPesquisador-Intérprete e, por fim, a elaboração da obra artística.

Palavras-chave: Método BPI. Estruturação da personagem. Dança do Brasil.

\section{ABSTRACT}

This article explores the experience and thoughts about the trajectory in a creative process on Dancer-Researcher-Performer method, explaining how the method functions through a performer's experience in it. It approaches field researches developed among baianas of samba schools in Jundiai city (state of São Paulo) and the Congado party, in Arturos community, in Contagem city (state of Minas Gerais), and also the Character's Incorporation process in the method, and finally the artistic work elaboration.

Keywords: BPI method. Character organization. Brazilian dance.
Mestranda em Artes da Cena pela Universidade Estadual de Campinas. Contato:

mjmaranzatoalves@gmail.com ORCID: http://orcid.org/ oooo-0001-8703-9167 2.

Professora do Programa de Pós-Graduação em Artes da Cena e do Curso de Graduação em Dança, do Departamento de Artes Corporais da Universidade Estadual de Campinas. Doutora em Artes pela Universidade Estadual de Campinas. Contato:

1.turtelli@gmail.com ORCID: http://orcid.org/ 0000-0003-4957-0816

Submetido em: 11/10/2016, aceito em: 03/11/2016. 
Este artigo apresenta o processo de pesquisa práticoteórica de criação do espetáculo "Quem vem nesse mar?"3 e os resultados referentes a ele. Esse processo se inicia com as pesquisas de iniciação científica "A Dança das Baianas das Escolas de Samba"4 e "Lágrimas de Marias"5, ambas realizadas a partir do método Bailarino-Pesquisador-Intérprete (BPI), durante o curso de Graduação em Dança da pesquisadora (Instituto de Artes/ Unicamp).

O projeto "A Dança das Baianas das Escolas de Samba" propôs a realização de um estudo aprofundado sobre as movimentações das baianas de escolas de samba da cidade de Jundiaí-SP, por meio do método BPI, focando no eixo Co-habitar com a Fonte, o qual envolve principalmente pesquisas de campo e laboratórios dirigidos, os dojos. Segundo Rodrigues e Muller,

Os estudos de imagem corporal consideram ao redor do corpo uma extensão do corpo por ser uma esfera de sensibilidade especial. Segundo Paul Schilder, do ponto de vista psicológico, os arredores do corpo são animados por ele. Em dança, este espaço significa um espaço pessoal que, segundo Laban, é chamado Kinesfera. Em tradições orientais este espaço em torno do corpo é chamado de dôjo, espaço este que o guerreiro deve cuidar para que não seja invadido pelo inimigo por ser parte de seu corpo (RODRIGUES, MULLER, 2006, p. 136).

Os laboratórios dirigidos são elaborados pela diretora com o intuito de que ocorram experimentações das movimentações vividas em campo e o reconhecimento do material de pesquisa no corpo do intérprete. Segundo a teoria da área, o eixo Co-habitar com a Fonte "possibilita uma rica interação entre corpos [...] O pesquisador, ao estabelecer uma fina sintonia no contato com o outro, poderá sintonizar-se consigo mesmo e se conhecer" (RODRIGUES, 2003, p. 105).

Dando continuidade ao projeto anterior, o "Lágrimas de Marias" desenvolveu um estudo no eixo Estruturação da Personagem do método BPI, visando chegar à sua incorporação, e desenvolvimento de um roteiro de movimentos sensações e sentidos fundamentado pelos conteúdos trazidos por ela, assim como à elaboração de uma obra artística e apresentação da mesma ao público.

Este artigo traz uma nova reflexão em torno do método BPI, expondo a trajetória de uma intérprete que vivenciou o método em seu corpo por dois anos. Fala-se de uma nova reflexão, pois dentro do BPI não existe um modelo fixo de como cada processo deve acontecer: existe um método que traça um caminho, apresenta eixos, ferramentas e procedimentos, porém esse percurso individualiza-se de pessoa para pessoa.
3.

O espetáculo "Quem vem nesse mar?", foi apresentado ao público em dezembro de 2014, no Instituto de Artes da Unicamp. O mesmo teve direção da Profa. Dra. Larissa Sato Turtelli, assessoria artística da Profa. Dra. Graziela Rodrigues, assistência de direção da doutoranda Elisa Costa e produção do Grupo de Pesquisa BailarinoPesquisador-Intérprete (BPI) e Dança do Brasil.

4.

Iniciação Científica com Bolsa FAPESP, proc. 2012/09825-O, orientada pela Profa. Dra. Larissa Sato Turtelli, no período de 2012 a 2013.

5.

Iniciação Científica com Bolsa FAPESP, proc. 2013/14765-9, orientada pela Profa. Dra. Larissa Sato Turtelli, no período de 2013 a 2014. 
O método BPI, criado pela Profa. Dra. Graziela Rodrigues, é formado por três eixos: o Inventário no corpo, Co-habitar com a Fonte e Estruturação da Personagem, os quais são amparados por cinco ferramentas (Técnica de Dança, Técnica dos Sentidos, Laboratórios Dirigidos, Pesquisas de Campo e os Registros) que auxiliam o intérprete na "realização corporal que irá produzir uma Arte gerada no cerne do corpo da pessoa" (RODRIGUES, 2010, p. 1).

O Inventário no corpo é o primeiro eixo a ser trabalhado no método. Nele, o intérprete realiza uma pesquisa em torno de seu histórico familiar e cultural, a fim de auxiliar o despertar de sua memória corporal, além de contribuir na criação ou aumento do vínculo com sua história de vida, como nos mostra Rodrigues: "Nessa fase introdutória, a memória do corpo é ativada, possibilitando que ao longo do processo ocorra uma autodescoberta quanto às próprias sensações, sentimentos, história cultural e social"' (RODRIGUES, 2003, p. 79).

Como parte do aprofundamento no método e na compreensão do Inventário no Corpo ocorre o trabalho da Técnica de Dança do método BPI, chamada de Estrutura Física e Anatomia Simbólica. Essa técnica trabalha todo o corpo usando o forte enraizamento dos pés, bacia pesando para o chão, soltura das escápulas, movimentos com o quadril que remetem ao símbolo do infinito $(\infty)$, entre outros.

A Estrutura Física também auxilia o intérprete a se preparar para o próximo eixo do método o Co-habitar com a Fonte. O enraizamento adquirido na Estrutura Física amplia a percepção do corpo do bailarino e dos sentidos, deixando-o, assim, aberto e sensível, pronto para coletar dados sobre si próprio e sobre o ambiente. Tal percepção é importante, pois, segundo Rodrigues (2003, p. 111), "No cotidiano do Co-habitar com a Fonte as relações de contato do bailarino com seu próprio corpo são fundamentais. O enraizamento deste contato e sua expansão favorecem a ampliação do olhar com todo o corpo".

A Estrutura Física é, então, usada também para que o bailarino-pesquisador-intérprete decodifique a movimentação vista em campo. Através dela, é possível analisar a penetração dos pés no solo, o direcionamento e movimentos do sacro e da parte superior da coluna e a formação do eixo-mastro.

No eixo Co-habitar com a Fonte, o intérprete escolhe uma pesquisa de campo a ser realizada. Tais escolhas - o que pesquisar e onde pesquisar - "são determinadas por motivações internas de cada pesquisador" (RODRIGUES 2003, p.106).

Minha primeira pesquisa de campo no método foi com Baianas de Escolas de Samba, na cidade de Jundiaí. Durante 
essas visitas a campo, tive uma dificuldade em encontrar as baianas presentes em todos os ensaios, já que eram poucas aquelas que frequentavam a escola assiduamente desde o período inicial da pesquisa.

Aprendi a lidar com o sentimento de frustração que começou a me tomar durante os primeiros meses de pesquisa e, aos poucos, fui percebendo que as baianas podiam não estar presentes de corpo nos ensaios, mas eram mencionadas sempre, com respeito e admiração. Nos meses mais próximos ao carnaval, as baianas começaram a frequentar mais a escola e pude perceber o quão importante elas eram naquele cenário.

Durante a pesquisa deparei-me com as baianas como sendo um vínculo entre passado e presente, como quando uma baiana ensinava algumas crianças a sambar ou quando as baianas dançavam rodeadas pelas crianças e depois iam cuidar delas. Era notável o cuidado e o carinho que tinham por elas. Essa amorosidade das baianas, como as "pretas-velhas"6 da escola, foi também um aspecto marcante de meu Co-habitar com a Fonte. Segundo me disse uma das baianas, elas são a raiz da escola, as pretas-velhas da escola, e aquele é o lugar onde elas celebram a vida, pois a história de seu povo está em cada pedacinho do terreiro da escola de samba.

No âmbito dos movimentos das baianas, pude observar diferentes qualidades nos corpos pesquisados. Os movimentos mais marcantes foram os giros e os gestos das mãos. Nos giros, as baianas começam a girar lentamente usando os grandes apoios dos pés (calcanhar, metatarso e dedos). Em cada giro ganham mais impulso; os pés começam a usar os pequenos apoios (desdobramentos dos grandes apoios) e o giro vai ficando cada vez mais rápido. No giro de menor impulso, a saia da baiana faz um movimento de ondas, ganhando, portanto, um balanço que transmite um sentimento de tranquilidade. Outro movimento importante é o gesto das mãos da baiana. Esses gestos podem ser de mostrar-se, exibir-se, acenar para as pessoas, apoiar as mãos no quadril e de oferecer ou receber algo.

Alguns dias antes do desfile de carnaval, as baianas e a coordenação da Leões da Hortolândia (escola na qual intensifiquei minhas pesquisas) perguntaram se eu gostaria de desfilar junto à ala das baianas. Nesse momento me senti parte daquela comunidade, porém na dúvida de como proceder, uma vez que não sabia se enquanto pesquisadora me caberia desfilar de baiana ou se isso atrapalharia minha observação num momento tão importante da pesquisa, e também o quanto isso me deixaria envolvida com o campo.

A orientadora do projeto, Profa. Dra. Larissa Sato Turtelli, conversou comigo sobre essa questão, o contexto no qual ela ocorreu, para me auxiliar a fazer a escolha entre desfilar ou não.
6.

Estabelecemos, aqui, uma analogia com as entidades "pretas-velhas" que se manifestam nos terreiros de Umbanda, religião brasileira de matriz africana. 
No BPI, a relação entre pesquisador e sujeitos de pesquisa durante o campo é delicada e deve ser estabelecida aos poucos, buscando relacionar-se com o outro, como também com as paisagens, as falas e movimentações corporais de cada pessoa, tendo-se sempre o cuidado para não invadir o espaço do outro.

Aceitei o convite feito para poder experienciar como é desfilar de baiana numa escola de samba, principalmente porque esse foi o momento em que me senti de fato aceita pelos membros da escola. Nesse momento o pesquisador está coabitando com a fonte e vivendo experiências que são absorvidas pelo corpo e, posteriormente, poderão vir à tona nos laboratórios dirigidos.

Por um momento o pesquisador vive aquela paisagem da pesquisa de campo como se pertencesse a ele. [...]. Nesse patamar ocorrem apreensões de elementos fundamentais, não verbais, que o corpo assimila e guarda e que só serão expressos no trabalho de laboratório (RODRIGUES, 2003, p. 107).

Pude perceber como as baianas são fundamentais para a escola: são uma referência de segurança, tranquilidade e acolhimento. Durante o desfile me questionei como as mais idosas estavam aguentando todo aquele peso nos ombros. Notei, então, que elas interagiam bastante com o público. Comecei a prestar atenção a isso e, quando as pessoas acenavam, eu acenava de volta, sorria, girava, e dançava à minha maneira. Notei então uma grande mudança no meu estado corporal. Era como se sentisse uma troca de energia com as pessoas com quem eu interagia, como se elas me dessem força para continuar desfilando.

Percebi que o "ser" uma baiana de escola de samba vai muito além de desfilar com uma grande saia. Envolve se doar inteiramente para aquele momento, abrir o olhar para as pessoas que estão assistindo ao desfile e permitir que haja uma troca com elas.

Outro momento marcante durante a pesquisa de campo aconteceu no final do desfile, quando as pessoas deixaram suas fantasias no chão da avenida. Nos laboratórios dirigidos, esse momento do abandono das roupas se mostraria importante e simbólico para o desenvolvimento do trabalho, como apresentarei posteriormente.

A pesquisa de campo foi intercalada com os laboratórios dirigidos, os dojos, que acolhem as impressões do intérprete em campo. Nos laboratórios dirigidos, aplica-se também a Técnica dos Sentidos, que ocorre no corpo do intérprete através de "circuitos de imagens/sensações/emoções/movimentos, não importando a ordem na qual eles se apresentem" (RODRIGUES, 2010, p.2). Tal circuito permite que o intérprete 
entre em contato com seus conteúdos corporais, reconhecendo-os e os integrando em sua dança.

No início dos laboratórios dirigidos, as paisagens, movimentos e corpos vivenciados nas pesquisas de campo começaram a vir à tona. As paisagens mais presentes foram a da quadra da escola de samba, o momento do desfile e o final da avenida onde ocorreu o desfile. Essas paisagens trouxeram diversas sensações e movimentos ao meu corpo.

Os conteúdos desencadeados em meu corpo transitavam entre mulheres de três gerações: a velha, a menina e a mulher. O corpo da velha aparecia, principalmente, na paisagem da quadra da escola. Era a baiana, que acolhia, dava a benção e comida para as crianças.

A menina trazia um conteúdo de abandono, com movimentações que traziam a ideia de "fechar" o corpo, querendo se esconder, sentindo-se sozinha. Ela aparecia na paisagem do final do desfile, onde as pessoas deixavam, no chão, as fantasias que haviam usado.

A mulher usava uma saia de espelhos e carregava um espelho na mão. Por esse objeto, enxergava as pessoas, algumas celebravam e outras choravam, pedindo ajuda. Eram, principalmente, mães que queriam encontrar seus filhos perdidos ou não tinham comida para dar a eles.

Assim, corpos de muitas mulheres "apareciam" em meu corpo, cada qual com suas especificidades. Os corpos são compreendidos dentro do método BPI como uma etapa a se passar para chegar à personagem; eles surgem a partir de uma ou mais modelagens: "um corpo no BPI representa uma síntese de conteúdos" (NAGAI, 2008, p.12, grifo no original).

Outra mulher que surgiu em meu corpo e trouxe conteúdos importantes para os laboratórios foi Nazaré, uma mulher brava que trazia essa aspereza para seus movimentos. Tinha um tônus corporal elevado e movimentos iniciados pelo impulso do quadril, como um chicotear.

Nazaré possuía uma ligação com uma santa. Vivia para cuidar e fazer festas para ela. Essa santa vinha da praia, por isso as pessoas tocavam tambor para chamá-la do mar. A santa vinha no corpo de Nazaré, trazia um movimento de ondular que partia do ventre; suas mãos eram feitas de espelhos e saía água delas. A santa procurava escutar as pessoas, mostrar seus reflexos com o espelho, acalmá-las e ajudá-las.

Durante o período dos laboratórios, confeccionei a santa de Nazaré. Feita de papel machê, tinha o corpo negro, seios fartos, usava um vestido azul e um manto prateado cobria a sua cabeça. A confecção da santa de Nazaré foi importante, uma vez que, em determinado momento do método BPI, faz-se necessária a materialização de objetos que estão presentes no 
imaginário da intérprete. Rodrigues explica: "Muitos dos elementos que vão surgindo, vindos internamente, são solicitados à própria pessoa que os confeccione, e passam a fazer parte do corpo de sua personagem, auxiliando-a na estruturação da mesma" (RODRIGUES, 2003, p. 130).

Assim, além de presente em meu imaginário, a santa passou a ser parte dos laboratórios e do corpo de Nazaré, permitindo então que essa fosse compreendida de forma mais estruturada. Entretanto, os conteúdos despertados em meu corpo nos laboratórios dirigidos indicaram que ainda era preciso que se realizassem pesquisas de campo complementares para auxiliar a dar vazão a esses conteúdos.

Voltar a campo é um procedimento previsto dentro do método BPI, já que as "pesquisas de campo complementares podem vir a ser necessárias, dependendo do conteúdo que for caracterizando a personagem" (RODRIGUES, 2003, p. 132).

Neste projeto, as pesquisas de campo complementares realizadas foram: com crianças de rua na Praça da Sé (em São Paulo), com mães na ONG Mães da Sé e no Congado na Comunidade dos Arturos, em Contagem, Minas Gerais.

Dentre essas pesquisas, a mais significativa foi a realizada com o Congado na Comunidade dos Arturos. As demais pesquisas foram importantes para o resultado final do processo que vivenciei, porém o campo dos Arturos foi aquele que proporcionou uma integração de todos os corpos que haviam surgido em meu corpo em um só, permitindo, assim, incorporar uma personagem.

A indicação para que fosse realizada uma pesquisa de campo complementar deveu-se aos conteúdos trazidos pelo "corpo" Nazaré. Ela tinha a pele negra e trazia em seu corpo uma forte relação com o tempo da escravidão, das correntes dos negros; trouxe também o mito da santa que vem do mar, de tocar o tambor na praia para chamá-la e de retirá-la do mar em seu corpo, processo estruturado durante os laboratórios dirigidos. A diretora desse processo (Larissa Sato Turtelli) identificou o mito que surgiu em meu corpo e informou-me que este está presente no Congado, indicando minha ida para a Comunidade Negra dos Arturos.

A Comunidade Negra dos Arturos fica em Contagem, Minas Gerais, e é formada pelos descendentes de Artur Camilo Silvério, um ex-escravo que se instalou naquela região. Os filhos de Artur permaneceram nas terras adquiridas pelo pai e lá constituíram suas famílias.

Nesse campo de pesquisa, foram feitos registros sobre as danças, os gestuais e as falas dos Arturos, envolvidos, na ocasião, com a festa de Nossa Senhora do Rosário. Pude observar as preparações para a festa, a festa em si e o depois da festa. Com 
as observações, notei que manter a ligação com seus ancestrais, festejar a resistência à escravidão e reafirmar a fé em Nossa Senhora do Rosário têm um significado vital para os Arturos.

Essa entrega intensa em relação às tradições ganhou grande destaque na pesquisa de campo, pois foi quando vi na prática que, para os Arturos:

[...] a dança existe em função da herança sagrada que se reatualiza com os desdobramentos do corpo. É a festa ritual, que escoando através dos ancestrais deságua nos músculos e na fé dos Arturosherdeiros: dançam porque creem em Nossa Senhora do Rosário, dançam porque a alegria e a dor foram também eleitas como um legado dos antepassados (RODRIGUES, 1988, p. 325).

Em determinado momento da pesquisa de campojá nos dias finais do Congado (a festa em si dura quatro dias), os mastros que haviam sido hasteados no primeiro dia foram retirados e as guardas retornaram para a comunidade. No caminho de volta, a guarda de Congo estava com uma grande força, parecia que eles retiraram também a força dos mastros e trouxeram para seu corpo. O canto estava alto, e até as mulheres mais adultas que não dançaram em nenhum momento estavam dançando, faziam a torção do corpo partindo do quadril enquanto cruzavam as suas pernas, foi o momento em que pude perceber a força de toda a guarda de Congo. Todos estavam lá naquele momento, com toda a potência de seus corpos.

Nas danças e gestuais dos Arturos fica evidente que cada uma de suas movimentações tem um significado e uma importância ímpar dentro da festa do Congado, confirmando a ideia de que "Não se trata de usar fórmulas repetidas, pois o corpo é construído no momento da ação, é um movimento vivo, único, relacionado ao estado de alma do dançador" (RODRIGUES,1988, p. 348).

Após a pesquisa de campo nos Arturos, ao entrar nos laboratórios dirigidos as movimentações que surgiram em meu corpo eram mais aprofundadas, possuíam mais sentidos e histórias para contar. A partir daí deu-se início a um segundo projeto de pesquisa: "Lágrimas de Marias", o qual teve como foco o eixo do método BPI Estruturação da Personagem. Esse eixo é iniciado quando, nos laboratórios dirigidos do Co-habitar com a Fonte, aparecem imagens de paisagens que começam a se repetir e a se ligar à imagem de "alguém" que habita nelas. Nesse momento,

Os dados das fontes de pesquisa (de campo e da pessoa) vão se desdobrando e se integrando. No momento em que ocorre o movimento-síntese, que esta associado a uma imagem-chave, a pessoa vê dentro de si características marcantes de uma personagem em seu espaço de origem (RODRIGUES, 2003, p.127). 
Aparecem, então, movimentos resultantes de imagens corporais que configuram o corpo de alguém imaginário. $O$ que se percebe nesse momento é que "As relações entre o mundo interno e externo promovem um processo de transformação da imagem corporal" (MELCHERT, 2007, p. 15). Por meio da Estruturação da Personagem, uma personagem é criada, fruto das relações pessoais do intérprete com o campo pesquisado. Citando Rodrigues, entende-se, então, que "A personagem emerge do Co-habitar com a fonte e do que essa vivência despertou na própria pessoa" (RODRIGUES, 2003, p. 121).A personagem é fruto da vivência de vários corpos que, durante os laboratórios de movimento, encontram uma maneira de se entrelaçar, permitindo, assim, chegar ao "momento em que ocorre a fusão dos corpos, que pronuncia uma personagem" (op.cit., p. 130).

A chamada Incorporação da Personagem no BPI ocorre quando "a pessoa alcança uma integração das suas sensações, das suas emoções e das suas imagens, vindas ate então soltas e desconectadas" (RODRIGUES, 2003, p.124). A sensação de ter o corpo dançando com toda sua potência e colocando em movimentos os conteúdos mais íntimos e profundos da intérprete traz uma sensação de vitalidade e força para o trabalho que vem sendo realizado.

Após a pesquisa de campo com os Arturos, com a continuidade dos laboratórios dirigidos, instaurou-se em meu corpo a personagem Sete Ondas: uma sereia com uma longa cauda de peixe, que possui muitos pedaços de algas, corais, plástico e rede enroscados nela; suas mãos são abertas, com barbatanas entre os dedos; seu rosto possui partes de pedra e os seios são fartos. A sereia tem em seu corpo ondulações que vão da cabeça à cauda, possui também movimentos que surgem de suas estranhas. Além disso, o baixo ventre possui vibrações internas que vão ganhando o restante do corpo.

A personagem Sete Ondas não excluiu os demais corpos que já haviam surgido durante os trabalhos anteriores; caracteriza-se como uma espécie de fusão deles. A aspereza de Nazaré e a relação que ela tinha com a santa, por exemplo, persistiram no corpo de Sete Ondas. Conteúdos do corpo da menina, que trazia os sentimentos de abandono e solidão, também se apresentaram na sereia. As ações com o espelho, de refletir e enxergar as pessoas também tiveram uma continuidade.

Em determinado laboratório dirigido ocorreu um momento que foi muito significativo para a história dessa personagem. Nele, eu possuía a imagem de estar num lugar cheio de água, tive a sensação de uma cauda começar a crescer a partir de minha barriga e de minhas pernas unirem-se de forma a virarem uma coisa só. Perdia as pernas e ganhava uma cauda. 
Para tornar a sensação dessa cauda mais presente, comecei a confeccioná-la sem o compromisso de reproduzi-la igualmente à imagem que tinha dela, mas pensando que ela era parte do corpo de minha personagem. Costurei em um tubo de tecido, em que colocava minhas pernas, partes de redes de pesca, lacres de latinha, pedaços de sacos plásticos e pedaços de flores artificiais.

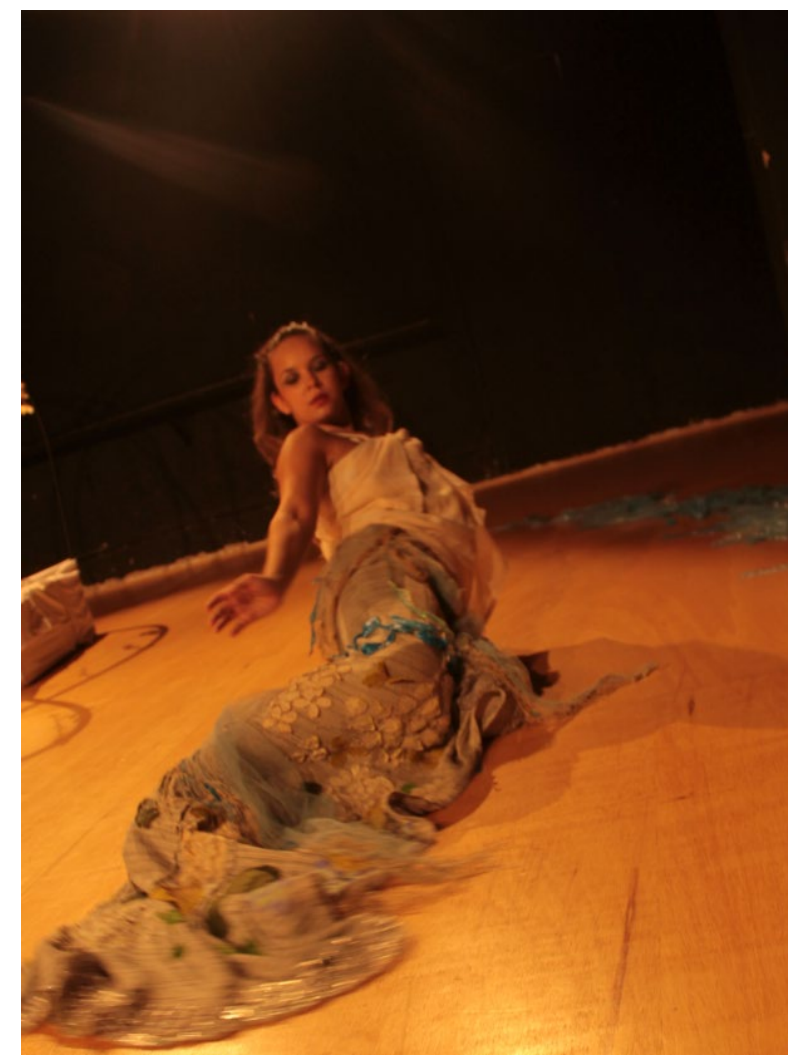

Figura 1.

Ensaio do espetáculo "Quem vem nesse mar?". Departamento de Artes Corporais da Universidade Estadual de Campinas (Unicamp). Campinas, 2014. Foto de Nara Cálipo.

Além dos movimentos que eram parte do corpo da sereia, Sete Ondas tinha movimentações de tremores, pulsar, pequenos pulos, rolamentos e ondulações do tronco.Cada um desses movimentos era mais característico de uma vivência particular da personagem.Dessas vivências e movimentações, alguns se fizeram presentes até o final do processo, enquanto outros conteúdos foram se modificando durante os laboratórios.

Uma das dificuldades dessa etapa da pesquisa era conseguir trazer com maior profundidade e habilidade a modelagem corporal da sereia para o meu corpo. Aprendi a lidar com essa dificuldade e a procurar os meios mais propícios para trazer a personagem para o corpo, buscando, por exemplo, um ajuste do tônus corporal, a sensibilização de cada parte do corpo, ou o exercício de colocar e retirar a personagem do corpo, procurando perceber como ela estava naquele dia de trabalho. 
[Nessa dinâmica] de trazer e retirar a personagem ocorrem novas descobertas tanto numa ação como na outra. Muitas vezes a personagem irá se revelar com maior clareza durante o movimento de retirada, pois o que sai do corpo irá ocupar um determinado lugar no espaço que vem sendo criado desde o início desta etapa (RODRIGUES, 2003, p. 130).

Num segundo momento do trabalho, após os conteúdos da sereia surgirem, alguns deles começaram a se repetir. Deu-se início, então, à construção de um roteiro para a realização do espetáculo. Esse roteiro foi sofrendo modificações durante o processo, sendo elaborado pelas professoras Larissa Turtelli e Graziela Rodrigues. No método BPI,

O roteiro emoldura um grande volume de representações, tendo como objetivo primeiro a fluidez do bailarino-pesquisador-intérprete. Neste caso, há uma preocupação quanto á clareza do que se quer expressar, relativizando a interferência do roteiro que, quanto à perspectiva de espetáculo, fica em segundo plano; isto no sentido de que não existem estratégias para encobrir os limites do intérprete nem tampouco uma construção formal que não esteja integrado a ele (RODRIGUES, 1997, p.149).

No roteiro final do espetáculo "Quem vem nesse mar?", a personagem Sete Ondas expressa os principais conteúdos trazidos por ela, os quais foram sendo interligados a contextos mais amplos, relacionados às pesquisas de campo realizadas. No início do roteiro a sereia traz à tona sua vaidade, enfeitando-se e banhando-se em um mar de lixo. Tem seu corpo grávido, com suas vísceras mexidas pelo bebê que abriga dentro de si. Luta para parir esse bebê e o perde. São vários os bebês perdidos. A santa vem em seu auxílio, acolhendo também os negros que morreram nas travessias do mar, a sereia dança com a santa em seu corpo. Chegando aos dias de hoje, Sete Ondas está na rua, na sarjeta, enxergando as pessoas através de seu espelho. A personagem procura suas crianças desaparecidas e chora a perda delas. Seu choro inunda todo o espaço e ela é tragada pelo mar. A sereia ganha pernas e consegue caminhar até a areia, abrindo o peito e os braços para acolher os que conseguirem enxergá-la. De peito aberto, retorna ao mar, ao qual ela pertence.

Os conteúdos trazidos pela personagem Sete Ondas relacionam-se a diversos aspectos da pesquisa de campo, especialmente à força de resistência e à devoção à Nossa Senhora, a qual abarca conteúdos ligados à maternidade, como os sentimentos de cuidado e acolhimento. A sereia também traz à tona questões da contemporaneidade como a perda da fé, a indiferença das pessoas com o próximo e o preconceito com o diferente, com aquilo que é "estranho" a si mesmo. 
A equipe de direção teve um papel fundamental durante todo o processo. No caso da estruturação do roteiro, por exemplo, a intérprete estava tão imersa dentro dos conteúdos da personagem Sete Ondas que era difícil refletir sobre quais conteúdos da sereia iriam ou não para a cena. Nesse momento, é a direção quem percebe os conteúdos mais insistentes e significativos no corpo da personagem e passa a elaborar o roteiro a partir deles, procurando dar-lhes amplitude e visibilidade. Nesse processo outros conteúdos são adicionados pela direção, no entanto são sempre pautados pelo universo trazido pela personagem.

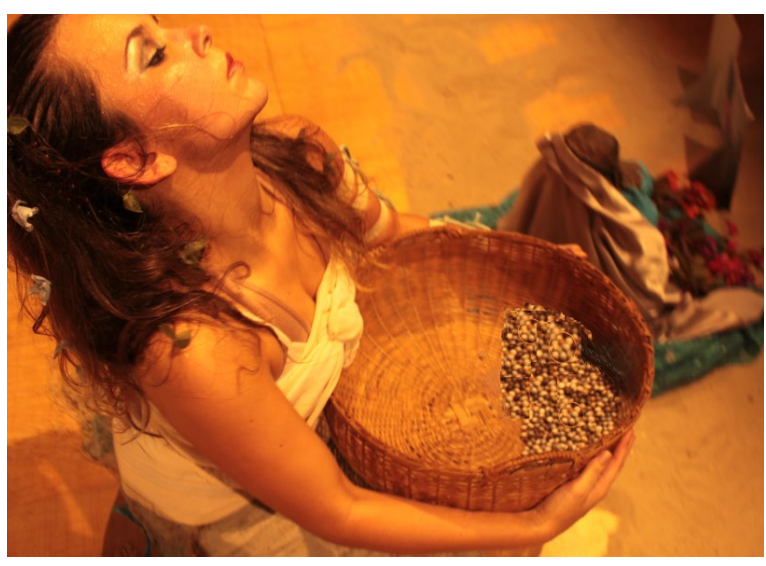

Figura 2.

Ensaio do espetáculo "Quem vem nesse mar?". Departamento de Artes Corporais da Universidade Estadual de Campinas (Unicamp). Campinas, 2014. Foto de Nara Cálipo.

A sensação de ter a personagem estruturada e incorporada propicia uma experiência muito especial para o intérprete, afinal ela nasce de um mergulho do Intérprete dentro de si. Durante os laboratórios Sete Ondas possibilitou-me entrar em contato com conteúdos que estavam presos dentro de mim, os quais não iriam necessariamente para a cena, contudo, vivenciá-los me proporcionou uma evolução e amadurecimento enquanto Intérprete.

A evolução de minha dança, alcançada através de um longo período de estudo, vivências e pesquisas, deu-se principalmente pelas características do método BPI, em que, por meio de paisagens, movimentos, sensações e emoções (fluxo dos sentidos) busca-se chegar a um corpo que dança integralmente, isto é, cujo movimento é iniciado internamente, mas atinge o corpo como um todo, permitindo que o intérprete alcance uma veracidade em sua dança.

Aprendi a ser paciente comigo, entendendo que, às vezes, é necessário um tempo para que o corpo encontre uma real ligação do movimento com os sentidos, pois no meu caso, era mais fácil o corpo entrar em um automatismo de movimentos e em uma representação dos sentidos do que viver de fato as sensações e emoções e deixar que o movimento ocorresse a partir delas, vindo de dentro para fora do corpo. Tal aprendizado proporcionou um aumento de minha per- 
cepção corporal, de forma a perceber quando o corpo ainda não chegou num tônus ideal para o trabalho, ou quando as imagens, sensações e sentimentos não estão interligados com os movimentos.

Apresentar a personagem Sete Ondas e seus conteúdos para o público gerou novas sensações e perspectivas em relação ao método BPI. O contato da personagem com o público desencadeou em meu corpo uma elevação de tônus e uma gana maior de compartilhar suas sensações, sentimentos e histórias. Nos dias de apresentação, sentia todas as experiências vivenciadas durante o processo passando pelo meu corpo e unificando-se dentro dele, trazendo um amadurecimento corporal, e com isso uma maior consciência e domínio sobre meu corpo. Tais circunstâncias me possibilitaram sentir e manter a personagem no corpo em um nível de profundidade que nunca havia atingido durante os laboratórios dirigidos.

Após assistirem o espetáculo "Quem vem nesse mar?" algumas pessoas questionaram-me sobre a questão da consciência durante o trabalho, argumentando que minha entrega para os conteúdos da personagem era muito intensa, e por vezes parecia para eles que eu estava "incorporada", sem consciência. Faziam uma associação com a incorporação num viés religioso, questionando-me se era eu que estava dançando ou se havia "baixado o santo".

De fato, no método BPI existe a incorporação da personagem, a qual, no entanto não possui conexão com questões religiosas. O momento da incorporação é aquele em que o corpo atinge uma potência decorrente de um abrir-se para o outro (no eixo Co-habitar com a Fonte), de uma disponibilidade para um contato profundo consigo mesmo, gerando assim, uma abertura para vivenciar conteúdos de diferentes realidades sociais. "Pode-se então afirmar que 'Sim', a intérprete está incorporada, no entanto não se trata de um 'Santo' vindo de fora da pessoa, e sim, um conteúdo fruto de interações" (TURTELLI, RODRIGUES, 2013, p.5). Dessa dinâmica entre o que é coletivo e a singularização disso no corpo do intérprete, da qual fazem parte tanto memórias individuais, quanto coletivas e todo um campo emocional, resulta uma qualidade de movimento diferenciada, cuja potência é percebida pelo espectador.

No método BPI, para o trabalho ser inteiro e chegar até o público é necessária uma entrega do intérprete aos conteúdos de seu personagem; no entanto, é fundamental que o mesmo esteja plenamente consciente de seu corpo e de todo o circuito de imagens, sensações, movimentos e sentimentos que ocorrem nele. 
Através do método BPI vivencia-se o conviver, observar e analisar outros corpos nas pesquisas de campo para se atingir a integridade dos muitos que vivem em cada um de nós. Quando essa integridade é atingida, o intérprete experiencia um momento muito especial e particular, no qual a personagem passa a dançar em seu corpo. A personagem é, assim, uma representante desse coletivo, trazendo em si a força presente em determinado segmento social, ao mesmo tempo em que é extremamente singularizada no corpo do intérprete no qual ela se concretizou. Ao longo dos processos de estruturação e de incorporação da personagem no método BPI foi possível sentir os conteúdos que vivem em mim sendo transformados em movimentos. Assim, sinto, por meio do fluxo dos sentidos, que a personagem é parte de mim, pois todas as suas características surgiram a partir de minhas vivências em campo e de meu processo dentro do método, ela se relaciona à minha essência. Por outro lado, ela é também maior do que eu, na medida em que diz respeito a todo um campo social que vai além do meu corpo individual.

Pude entender nesse percurso que é preciso uma abertura e uma grande disponibilidade por parte do intérprete para que o processo ocorra de forma profunda e verdadeira, isto é, sem dissimulações. O intérprete precisa estar disposto a entrar em contato com os conteúdos que vivem em si, caso contrário acaba ocorrendo um bloqueio do processo criativo, com repetições e despistes, ao invés de um fluxo dos movimentos, sentimentos, imagens e sensações.

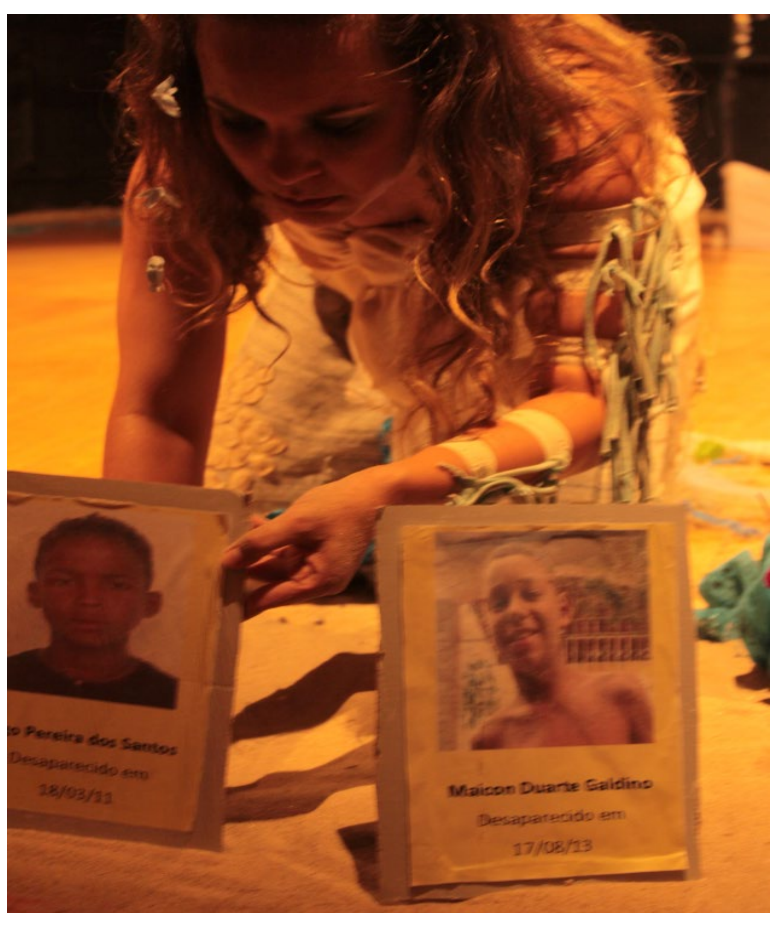

Figura 3.

Ensaio do espetáculo "Quem vem nesse mar?". Departamento de Artes Corporais da Universidade Estadual de Campinas (Unicamp). Campinas, 2014. Foto Nara Cálipo. 
O fluxo dos sentidos do método BPI é priorizado em relação ao produto final, esse é uma consequência do processo que ocorreu no corpo do intérprete. O processo dentro do método varia sua temporalidade e o modo que vai ocorrer de acordo com cada pessoa, existe um método e técnicas dentro dele a serem seguidas, porém dentro do BPI, enxerga-se cada pessoa enquanto um indivíduo. 


\section{REFERÊNCIAS}

MELCHERT, Ana Carolina Lopes. O Desate Criativo: Estruturação da Personagem a partir do método BPI (BailarinoPesquisados-Intérprete). 2007. Tese (Mestrado em Artes) - Instituto de Artes, Universidade Estadual de Campinas, Campinas, 2007.

NAGAI, Angela Mayumi. O Dojo do BPI: Lugar onde se desbrava um caminho. 2008. Dissertação (Mestrado em Artes) - Instituto de Artes, Universidade Estadual de Campinas, Campinas, 2008.

RODRIGUES, Graziela Estela Fonseca. Bailarino-PesquisadorIntérprete: processo de formação. $2^{\mathrm{a}}$ ed. Rio de Janeiro: Funarte, 2005. 182 p. ISBN 85-85781-41-6.

RODRIGUES, Graziela Estela Fonseca. O Método BPI (BailarinoPesquisador-Intérprete) e o desenvolvimento da imagem corporal: reflexões que consideram o discurso de bailarinas que vivenciaram um processo criativo baseado neste método. 2003. Tese (Doutorado em Artes) - Instituto de Artes, Universidade Estadual de Campinas, Campinas, 2003.

RODRIGUES, Graziela Estela Fonseca. As Ferramentas do BPI (Bailarino-Pesquisador-Intérprete). In: Simpósio Internacional e Congresso Brasileiro de ImagemCorporal, 1., 2010, Campinas. Anais do... Campinas: Universidade Estadual de Campinas.

RODRIGUES, Graziela Estela Fonseca. In: GOMES. N. e PEREIRA. E. Negras raízes mineiras: os Arturos. 1988. Juiz de Fora: Ministério da Cultura, EDUFJF, 1988.

RODRIGUES, Graziela Estela Fonseca, MULLER, Regina. Dança dos Brasis: as mulheres de cócoras. Cadernos da Pós-Graduação, Campinas (Instituto de Artes Unicamp), vol. 8, no.1, 2006.

TURTELLI, L. S. e RODRIGUES, G. E. F. Baixou o santo? VII Reunião Científica da ABRACE. Belo Horizonte. MG, 2013. 